\title{
Antimicrobial resistance global emergence: healthcare facilities or environmental microbiota as the most important reservoir of antibiotic resistant microorganisms?
}

\author{
Roberta Migliavacca, ${ }^{1}$ Vittorio Sambri ${ }^{2,3}$ \\ ${ }^{1}$ Department of Clinical, Surgical, Diagnostic and Pediatric Sciences, Unit of Microbiology and \\ Clinical Microbiology, University of Pavia; ${ }^{2}$ Microbiology Unit, Romagna Local Health Unit, \\ Pievesestina; ${ }^{3}$ DIMES, University of Bologna, Italy
}

The ecosystems contamination caused by drugs and by their biologically active transformation products has become an emerging environmental issue: recently developed analytical and sensitive methods have allowed the detection of these pollutants in different matrices (like water, soil, sediment).

Given that, such molecules are characterised by both a relative persistence in the body and a high biochemical reactivity (most of them are able both to cross the biological membranes and to exert therapeutic action on cellular specific target sites even at very low concentrations), their presence in the environment (although in the range of $n g / L$ to $\mu \mathrm{g} / \mathrm{L}$ ), could represent a risk to the human and ecosystems health.

In this regard, if certain drugs are of particular concern due to their features as endocrine disruptors (e.g. some synthetic steroid hormones) others, such as antibiotics, are worrisome for their ability to induce drug resistance in clinically relevant microorganisms.

The latter phenomenon is particularly alarming, as it can affect therapeutic treatments in severe patients with the consequent spread of infections in the healthy population.

Correspondence: Roberta Migliavacca, Department of Clinical, Surgical, Diagnostic and Pediatric Sciences, Unit of Microbiology and Clinical Microbiology, University of Pavia, Via Brambilla 74, 27100 Pavia, Italy. Tel.: +39.0382 .984143 - Fax: +39.0382 .5484255 .

E-mail:r.miglia@unipv.it

Key words: Antimicrobial resistance; reservoirs; risk of transmission.

Contributions: RM wrote the manuscript, VS revised the paper.

Conflict of interest: the authors declare no potential conflict of interest.

Received for publication: 3 June 2016.

Accepted for publication: 3 June 2016.

CC Copyright R. Migliavacca and V. Sambri, 2016

Licensee PAGEPress, Italy

Microbiologia Medica 2016; 31:6045

doi:10.4081/mm.2016.6045

This article is distributed under the terms of the Creative Commons Attribution Noncommercial License (by-nc 4.0) which permits any noncommercial use, distribution, and reproduction in any medium, provided the original author(s) and source are credited.
Urban, hospital and pharmaceutical industry wastewater treatment plants are among the main sources of antibiotic and antibiotic resistant bacteria contamination in soil and water ecosystems (12).

These contaminants, that can survive the wastewater treatment processes, can reach water resources for drinking water production, enter the food chain (if irrigation with wastewater effluents is applied) or reach clinically relevant niches (19).

Several studies have shown the impact of feeding antibiotics as growth promoters for livestock animals, on resistance to clinically relevant antibiotics: it is well known that only when avoparcin was banned for use as a growth promoter in the EU Member States in April 1997, the number of vancomycin-resistant enterococci in both animals and humans decreased in EU countries $(2,13)$.

The success of drug resistance versus susceptibility, and therefore the probability to have a dissemination of resistant clones, depends mainly on the global fitness of single germs.

It is generally assumed that the acquisition of a resistance phenotype confers a fitness advantage when the germ is exposed to antibiotic treatment, but that it entails a fitness cost in absence of antibiotics (16); this highlights the importance of avoiding antibiotic misuse in different settings.

Microorganisms have shown an enormous capacity to evolve towards resistance, and a huge genetic plasticity.

Bacteria efficiently recruit and mobilize antibiotic resistant genes by means of integrons, transposons and plasmids: these mobile genetic structures render gene transfer and capture so frequent that nowadays it is generally considered that any given bacterial species has a core genome, characterized by a stable content, and an accessory genome, in which genetic modifications happen frequently.

The mobilome (the total of all mobile elements in a genome) and the resistome (the collection of all the antibiotic resistance genes and their precursors in both pathogenic and non-pathogenic bacteria) usually follow parallel paths, and in the pan-genomes of clinically important bacteria, antimicrobial resistance determinants are now worryingly prevalent.

This is usually generated as the effect of the excessive use of antibiotics in both human and veterinary settings, and release from different anthropogenic sources $(1,7,20)$.

Animals, either pets or livestock can play a major role in the origin of antibiotic resistant bacterial clones as well as acting as reservoirs thereof.

Transmission from animals to humans can occur through direct contact with living animals, but also through food - mainly meat derived from animals colonized with resistant bacteria. Food-borne resistance also allows, through worldwide imports and exports trade, for a relevant international circulation of resistance genes (9). 
Understanding the flux of resistance units, throughout the diverse ecosystems, is crucial to assess, prevent and eventually predict emerging scaffolds before their appearance as pathogenic germ in human patients. It is well known that the environment contribution to the enlarging spectrum of antibiotic resistance genes is extremely relevant.

This was the case for Kluyvera spp., commensal bacteria of both humans and animals, which went ahead to the mobilization of their chromosomal blaCTX-M-type beta-lactamase-encoding genes into plasmids of other bacterial species (4).

Another example in this regard is represented by the OXA-typebeta-lactamases. The first report of Shewanella xiamenensis carrying a bla0XA-48-like gene suggested that the emergence of different genes from this group had their origin in different $S$. xiamenensis strains (17).

The efficacy of bla0XA-48-like gene transfer between bacterial species in human cases has also been reported in food-producing, companion and wild animals, as well as in natural environments (18), thus highlighting the importance of this phenomenon in the dissemination of antibiotic resistance among different biological reservoirs.

The idea that selected resistance mechanisms, such as the production of carbapenemase enzymes, are only linked to infections in humans and in the healthcare facilities is no longer valid (14). Another example of this is the recently emerged plasmid-mediated polymixin resistance mechanism, MCR-1, firstly isolated from an Escherichia coli strain SHP45 of animal origin in China and now sporadically reported in Enterobacteriaceae from humans (10).

This emerging antimicrobial resistance mechanism has been recently detected also from a patient suffering from urinary tract infection in the USA (11): This fact is somehow worrisome since it means that this highly transferable gene, that has been hypothesized to circulate since a long time in $E$. coli, is widely spread among bacteria infecting animals and humans in Asia, Europe and America $(8,15)$.

It is now overwhelming the evidence that the release of antibiotics into the environment must be minimized in order to decrease the selective pressure on free ranging germs, and thus limit the emergence and selection of new resistance mechanisms: now more than in the past integrated approaches are required for the environmental management in this respect.

The development and implementation of national and international guidelines for the biological risk assessment of the emergence and propagation of antibiotic resistant bacteria in the environment is a strategic priority $(3,6)$.

A major limitation in determining the current risk of transmission of antibiotic resistance genes from the environment to human-associated bacteria is the insufficient knowledge on the distribution and abundance of antibiotic resistant bacteria and antibiotic resistance genes in the environment at national, regional or global levels. (3). Not only long-term surveillance reports on multi-drug resistant (MDR), clinical-derived strains have to be encouraged in Italy, but also national dimension studies to assess the prevalence of resistance mechanisms in the environmental compartments or ecosystems (beginning from soil and water). The available data, mainly coming from sporadic research studies, are indeed reporting on the worrisome emergence MDR bacteria carrying blaCTX-M-type genes in the streams of our countries (5).

In these conditions, the role of Clinical Microbiologist is very important, and from an additional perspective: in acting as a driving force for the implementation of a multidisciplinary international concerted action. Only achieving a better overall epidemiological knowledge and control of environmental and veterinary settings, the antimicrobial resistance vicious circle, that represents a major health concern for the near future, could be really understood and countered.

\section{References}

1. Allen HK, Donato J, Huimi H, et al. Call of the wild: antibiotic resistance genes in natural environments. Nat Rev Microbiol 2010;8:251-9.

2. Bager F, Madsen M, Christensen J, et al. Avoparcin used as a growth promoter is associated with the occurrence of vancomycinresistant Enterococcus faecium on Danish poultry and pig farms. Prev Vet Med 1997;31:95-112.

3. Berendonk TU, Manaia CM, Merlin C, et al. Tackling antibiotic resistance: the environmental framework. Nat Rev Microbiol 2015;13:310-17.

4. Bonnet R. Growing group of extended-spectrum beta-lactamases: the CTXM enzymes. Antimicrob Agents Chemother 2004;48:1-14.

5. Caltagirone M, Nucleo E, Spalla M et al. Detection of ESBL-producing Gram-negative bacteria from surface and ground-waters in the Po Valley. 2016; EP0208 e-poster at 26th ECCMID, 9-12 April, Amsterdam.

6. Cantas L, SQA Shah, LM Cavaco et al. A brief multi-disciplinary review on antimicrobial resistance in medicine and its linkage to the global environmental microbiota. Front Microbiol 2013;4:96.

7. D'Costa VM, King CE, Kalan L, et al Antibiotic resistance is ancient. Nature 2011;477:457-61.

8. Fernandes MR, Moura Q, Sartori L, et al. Silent dissemination of colistin-resistant Escherichia coli in South America could contribute to the global spread of the mcr-1 gene. Euro Surveill 2016;21.

9. González-Zorn B, Escudero JA. Ecology of antimicrobial resistance: humans, animals, food and environment. Int Microbiol 2012;15:101-9.

10. Liu YY, L, Wang Y, Walsh TR, et al. Emergence of plasmid-mediated colistin resistance mechanism MCR-1 in animals and human beings in China: a microbiological and molecular biological study. Lancet Infect Dis 2016;16:161-8.

11. McGann P, Snesrud E, Maybank R, et al. Escherichia coli harboring mcr-1 and blaCTX-M on a novel IncF plasmid: first report of mcr-1 in the USA. Antimicrob Agents Chemother 2016 [Epub ahead of print].

12. Michael L., Rizzo CS, McArdell CM, et al. Urban wastewater treatment plants as hotspots for the release of antibiotics in the environment: a review. Water Res 2013;47:957-95.

13. Pantosti A, Del Grosso M, Tagliabue S, et al. Decrease of vancomycin-resistant enterococci in poultry meat after avoparcin ban. Lancet 1999;354:741-2.

14. Patel G, Bonomo RA. Stormy waters ahead: global emergence of carbapenemases. Front Microbiol 2013;4:48.

15. Poirel L, Nordmann P. Emerging plasmid-encoded colistin resistance: the animal world as the culprit? J Antimicrob Chemother 2016 [Epub ahead of print].

16. San Millan A, Garcia-Cobos S, Escudero JA, et al. Haemophilus influenzae clinical isolates with plasmid pB1000 bearing blaR0B-1: fitness cost and interspecies dissemination. Antimicrob Agents Chemother 2010;54:1506-11.

17. Tacao M, Correia A, Henriques I. Environmental Shewanella xiamenensis strains that carry bla0XA-48 or bla0XA-204 genes: additional proof for blaOXA-48-like gene origin. Antimicrob Agents Chemother 2013;7:6399-400.

18. Woodford N, Wareham DW, Guerra B, et al. Carbapenemase-producing Enterobacteriaceae and non-Enterobacteriaceae from animals and the environment: an emerging public health risk of our own making? J Antimicrob Chemother 2014;69:287-91.

19. World Health Organization. Tackling antibiotic resistance from a food safety perspective in Europe. 2011. Available from: http:// www.euro.who.int/_data/assets/pdf_file/0005/136454/e94889.pdf

20. World Health Organization. Antimicrobial resistance: global report on surveillance. 2014. Available from: http://www.who.int/drugresistance/documents/surveillancereport/en/ 